\title{
Numerical Investigation of Façade and Floor Glazing Systems
}

\author{
Themistoklis Tsalkatidis ${ }^{1, a^{*}}$ and Magne Moastuen ${ }^{1, b}$ \\ ${ }^{1}$ Faculty of Science and Technology, Norwegian University of Life Sciences, Ås, Norway \\ athemistoklis.tsalkatidis@nmbu.no, bmagne.moastuen@nmbu.no
}

Keywords: façade glazing system, floor glazing system, glass.

\begin{abstract}
The use of point-supported systems in glass façades and floors has become widespread due to their excellent structural properties. The combination of glass and metal, frequently found in modern architectural norms and expressions, has highlighted the role of such systems and the need for constant optimization of their design. This research paper aims to examine the influence of modifying several geometrical parameters such as the thickness and the weight of the structural spider connectors, the arm-core ratio of the spider, the thickness of the glass panel and the spider arm cavities on the structural performance of a spider connector produced by one of the marketleading manufacturers. Therefore, a parametric finite element analysis is performed, where four alternative versions of the spider are constructed, in addition to the reference version, using ANSYS software program. The numerical model of the reference spider is verified against experimental data from the manufacturer of the structural spider connector. A total number of twelve case studies that consist of different combinations of spiders and glass' thickness are examined, five for the façade and seven for the floor glazing system. The focus of the numerical investigation is placed on the spider itself and the results of the parametric finite element analysis are presented and discussed. The effectiveness of having core cavities and hollowed-out arms in spiders is proven. The use of stronger but heavier spiders is an acceptable alternative if they are connected to larger glass panels that results in reducing the number of spiders without increasing significantly the total weight of the glazing system.
\end{abstract}

\section{Introduction}

The use of glass as a structural material has been steadily increasing due to its lightness and unique aesthetics, especially in the form of panels placed in façades and walkways of steel and hybrid buildings. A key design challenge for the structural engineer is to keep the internal support systems of the glass panels as minimum visible from the outside as possible, so that the glass appears to be continuous and flowing, thus satisfying the architectural composition demands. The structural spiders are parts of point support glazing assemblies that have replaced the formerly used glass systems. In glazing assemblies, both the connected parts- glass and metal- and the means of ensuring their connection have been topics of research and debate. Wang et al. [1] performed both an experimental and a numerical analysis of non-linear metallic spiders resulting in a new proposed design formulae, taking into consideration stress concentrations. A high order finite element model that describes the structural behaviour and response of non-rectangular glass plate is constructed by El-Shami et al. [2]. Rénes et al. [3] carried out pull-out tests of point fixed glass plates with diverse dimensions under quasi-static load, concluding that the size and the type of the glass decreases significantly the deformation of the glass plates. Whereas Wang et al. [4] studied a similar system with tempered glass subjected under different ratios of in-plane and out-of-plane load. Moreover, Sivanerupan et al. [5] performed a series of full-scale tests and numerical analyses of a typical point fixed glass façade system under dynamic loading conditions and concluded that the failure of the glass occurs at a top drift of $2.1 \%$. The state of the art related to performance of glass facades under extreme loads is presented by Bedon et al. [6] concluding that specific fail-safe design criteria need to be established, especially due to the brittle nature of glass as a construction material. Van Lancker et al. [7] investigated the use of adhesive glass-metal as an alternative to bolted connections in structural formations and Bues et al. [8] studied experimentally the effect of various geometries and loading conditions on the capacity of adhesive glass-metal joints. Vyzantiadou and 
Avdelas [9] presented the role of fractal geometry in the formation and structural performance of point fixed glazing systems whereas Aksamija [10] highlights the role of facades as key elements in efficient energy-driven design of modern buildings. The role of PVB interlayers in the overall behaviour and in the shear transfer mechanism of laminated glass plates- in particular - it is highlighted by Hana et al. [11]. Finally, Wang et al. [12] performed a series of parametric studies on embedded cable support (ECS) glass systems, concluding that the design of these systems is deflection governed and the use of preloaded cables is recommended in such systems.

\section{Theory}

Glass is a versatile building material that can be used in several forms and applications. The designer has the option to select the appropriate among different types of glass, such as monolithic glass, laminated, stained, mirror or safety glass and among different geometric formations such as square, triangular or polygonic, placed vertically, horizontally or inclined. The selection of glass is accompanied by the selection of a support system. The latter consists of two main parts, the frame and the point support system. The frame system is either made of steel beams and columns with slender profiles or load-bearing glass profiles. Another option is to use suspension wire systems [13]. Regarding the point support system, simple bolted connections with cantilevered cylindrical support members are sufficient for lightweight glass structures whereas in ordinary and heavier cases, the use of brackets with several arms known as structural spiders is the norm. Structural spiders are either clamped or bolted. Although the need of drilling holes in the glass, bolted fastened structural spiders are the ones who are usually selected. For investigating the influence of the modification of diverse geometrical parameters on the structural behaviour of a bolted spider system, three-dimensional numerical models using the finite element method are developed, for both façade and floor bolted spider glass systems. Emphasis is placed on the structural spider itself with the investigation of the effect of modifications of spider's sophisticated geometry on its performance set as being the primary goal [14].

In general, structural spiders must be sufficiently dimensioned in order to withstand significant loads, to sustain environmental induced corrosion, to allow a relative movement between the connected parts and even to provide adequate safety even after possible glass breakage.

\section{Materials and Methods}

The analysis presented and discussed is a numerical parametric study of a glazing system. The system under examination consists of a structural spider that it is connected by bolts to four glass panels, with the presence of sixteen spacers. The selected reference spider is S3001EVO, which is produced by Sadev. The numerical analysis is done using ANSYS version 18.2 finite element package and the reference spider is verified against experimental results from vertical and horizontal bending tests performed in the spider [15]. In order to increase the accuracy of the threedimensional representation of the spider, ANSYS SpaceClaim that is a CAD module integrated in ANSYS, and 3D rendering software KeyShot have been used [16, 17]. The geometry of the reference spider is shown in Fig. 1.

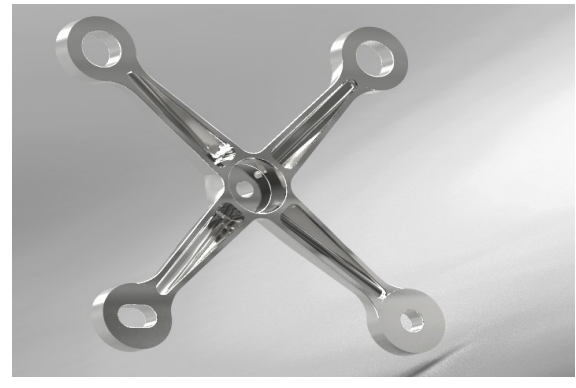

a

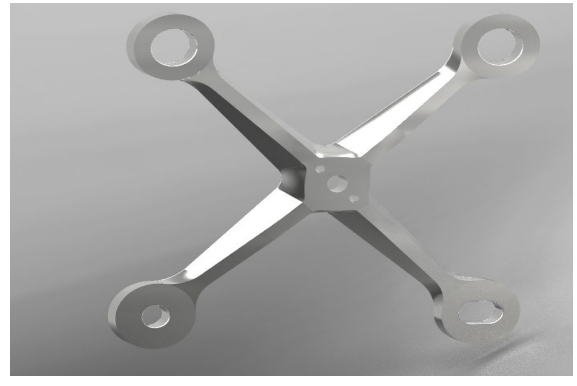

b

Figure 1. Rendering of the reference structural spider: a) Bottom part; b) Top part. 
As stated formerly, glass application is not only limited to façades but it is also used in floors, ceilings, stairs or indoor and outdoor walkways. Therefore, the same glazing system has been examined for horizontal placing under floor design loading conditions. The glass panels are rectangular and have dimensions 1860 by $2500 \mathrm{~mm}$ with minimum thickness of $20 \mathrm{~mm}$. Moreover, four modified versions of the spider are also constructed, as part of the parametric study, combined with different glass thicknesses. The different versions of the spider and their characteristics are presented in Table 1. The parameters changed in relation to the reference spider are the height and the thickness in addition to the investigation of a more solid shape.

Table 1. Structural spider versions under investigation.

\begin{tabular}{|c|c|c|c|}
\hline Spider & Modifications & Weight, [kg] & $\begin{array}{c}\text { Weight } \\
\text { difference, [\%] }\end{array}$ \\
\hline S3001EVO & Reference version & 1.428 & - \\
\hline Modified v1 & $\begin{array}{c}\text { Increased core section thickness } \\
\text { Shallower cavities }\end{array}$ & 1.529 & $7 \%$ \\
\hline Modified v2 & $\begin{array}{c}\text { Increased core section thickness } \\
\text { Increased height } \\
\text { Wider arms } \\
\text { Modified v3 }\end{array}$ & $\begin{array}{c}\text { Increased core section thickness } \\
\text { Increased height and wider arms } \\
\text { No arm cavitiess }\end{array}$ & 2.109 \\
\hline Modified v4 & $\begin{array}{c}\text { Increased core section thickness } \\
\text { Increased height and wider arms } \\
\text { Shallower cavities }\end{array}$ & 1.847 & $47.7 \%$ \\
\hline
\end{tabular}

The modified versions v1 and v2 of the reference spider are shown in Fig.2.

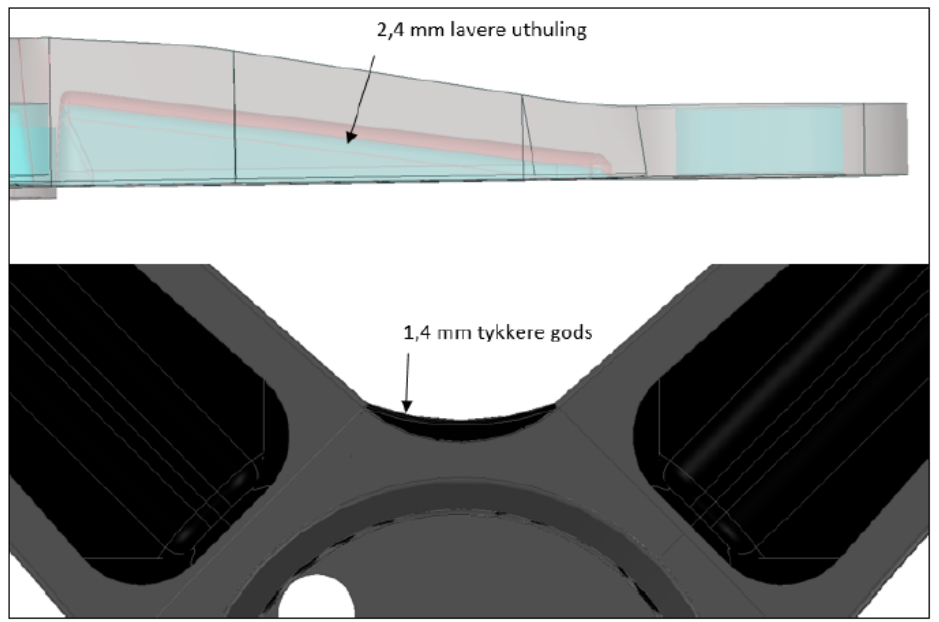




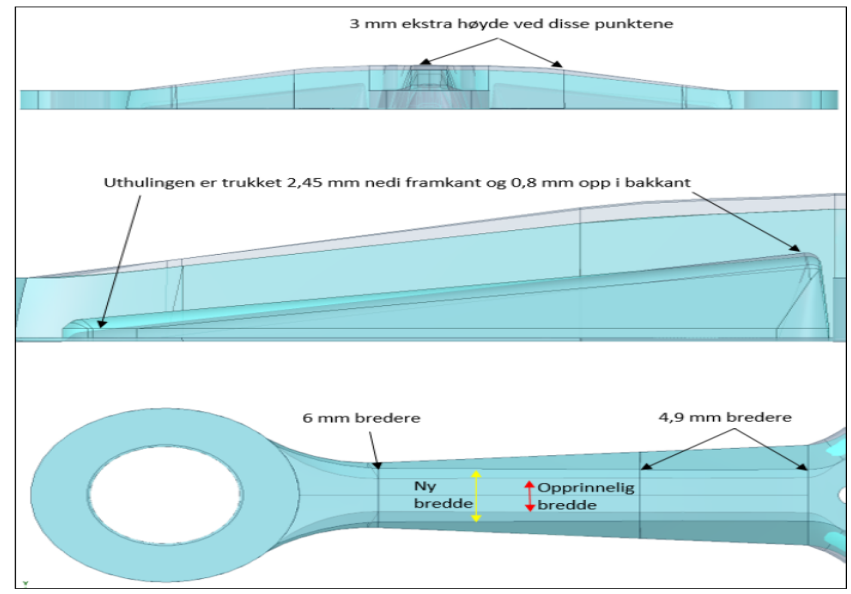

b

Figure 2. Modified spider versions: a) Version 1; b) Version 2.

The modified versions v3 and v4 of the reference spider are shown in Fig.3.

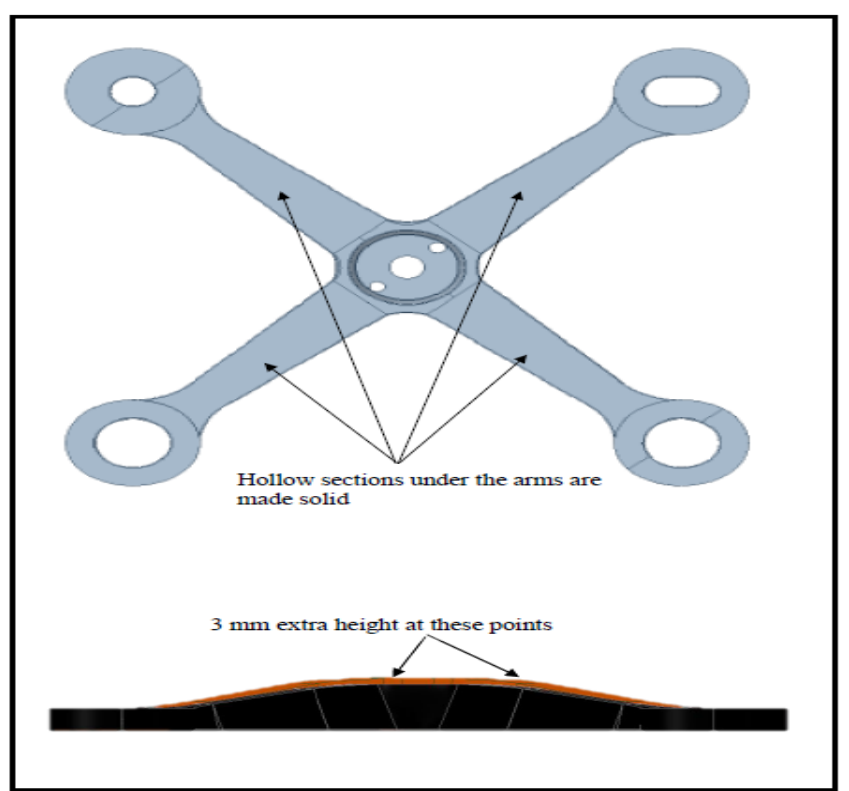

$\mathrm{a}$

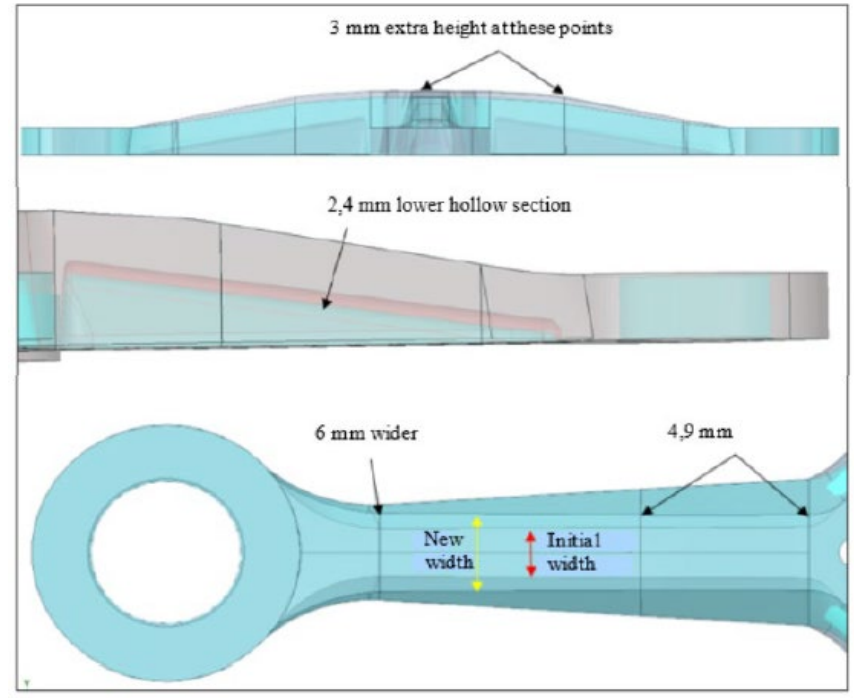

b

Figure 3. Modified spider versions: a) Version 3; b) Version 4. 
During the numerical simulations, the load is applied in static form and the calculation of the loads is done according to European standards [18-20]. Thermal effects have not been taken into consideration during the analysis. The service loads remain the same during the parametric investigation but the permanent load varies since the thickness of the glass panels changes. A total number of twelve case studies have been examined both for façade and floor system, as presented in Table 2. In case study 3 the pressure is acting as suction pressure in contrast to the other case studies where the pressure pushes the system.

Table 2. Case studies examined.

\begin{tabular}{|c|c|c|c|}
\hline Number & Placement & Spider & $\begin{array}{c}\text { Glass thickness, } \\
{[\mathbf{m m}]}\end{array}$ \\
\hline 1 & Façade & Reference & 20 \\
\hline 2 & Façade & Reference & 30 \\
\hline 3 & Façade (suction) & Reference & 20 \\
\hline 4 & Façade & Modified v1 & 20 \\
\hline 5 & Façade & Modified v1 & 30 \\
\hline 6 & Floor & Reference & 30 \\
\hline 7 & Floor & Modified v1 & 30 \\
\hline 8 & Floor & Modified v2 & 30 \\
\hline 9 & Floor & Modified v3 & 30 \\
\hline 10 & Floor & Modified v4 & 30 \\
\hline 11 & Floor & Modified v4 & 35 \\
\hline 12 & Floor & Modified v4 & 40 \\
\hline
\end{tabular}

Glazing assemblies consist of glass and steel, which are materials with quite different mechanical properties that need to interact and cooperate during the service life of a façade or a floor construction. Therefore, the quality of the materials used in these systems is important. Regarding the finite element models, the structural spider is simulated as having a stainless steel alloy of quality S316 Cr-Ni-Mo 19-11-2 with casted version CF8M, in accordance to the product details, whereas the float structural glass is considered to be float and heat strengthened. Regarding material properties, steel is modelled as having a bilinear isotropic hardening (BISO) material law, and for glass elastic properties are applied. The steel has yield strength of $290 \mathrm{MPa}$ and the glass has characterstic value of the fracture strength equal to $f_{b, k}=70 \mathrm{MPa}$. The inherent strength of the glass $\mathrm{f}_{\mathrm{g}, \mathrm{d}}$ is set to $39.3 \mathrm{MPa}$ for wind loads and to $28.1 \mathrm{MPa}$ for service loads. The resistance of the glass panel against lateral loads is calculated according to prEN 13474-3 [21].

The glass and the steel parts of the model are both modelled using solid structural elements from ANSYS element library, SOLID 187 element, a 20-node hexahedron is used for the spider part whereas SOLID 186 a 10-node hexahedron is used for the glass panel. No interlayers or glass layers are regarded since the glass panels are simulated as solid volumes The connection between the steel and the glass is simulated using contact elements, at their interface. In order to ensure connectivity, contact pairs that overlap the existing solid elements are created. For this model, CONTA 174 and TARGE 170 three-dimensional contact elements have been selected and the contact behaviour is simulated as having 'bonded' characteristics. The spacers are assigned polyethylene material properties with yield strength equal to $20 \mathrm{MPa}$. For simplicity reasons, the bolts are not modelled as individual volume elements but the support conditions applied in the 
numerical models simulate their effect. The load is applied in static load steps and the boundary conditions simulate simply supported conditions. The mesh size used in the model is equal to 6.2 $\mathrm{mm}$ which results in a total number of about 17500 elements and 31000 nodes for the reference model. Several mesh studies were conducted before the selection of the appropriate element dimension.

\section{Results}

The main outcomes of the numerical analysis are the measurement of the deformations of the structural spider and the glass panel together with the calculation of the corresponding equivalent von Mises stress for the spider and the maximum principal stress for the glass. The results are depicted in Figs. 4-7.

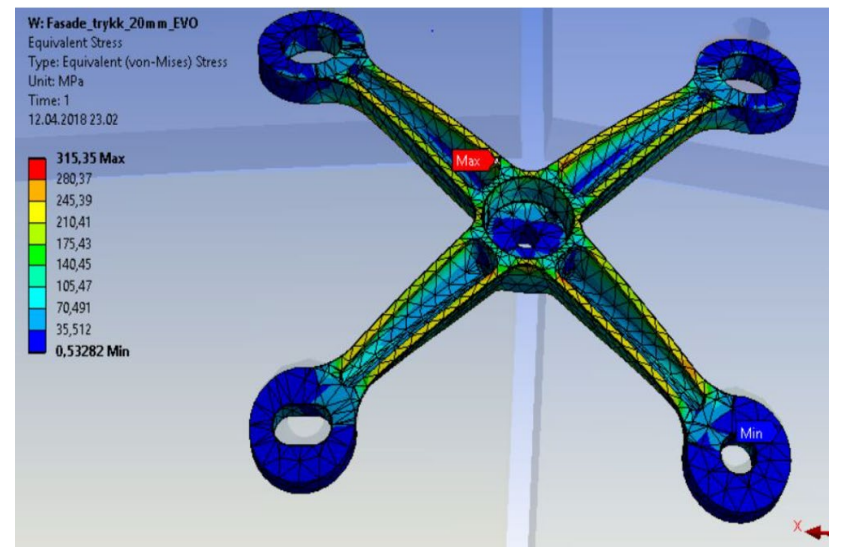

a

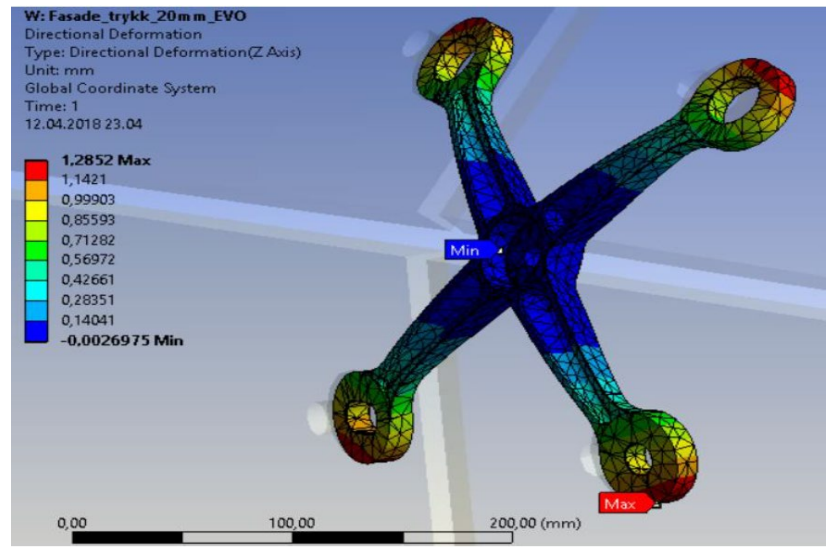

b

Figure 4. Case 1: a) Von Mises equivalent stress distribution; b) Spider deformation.

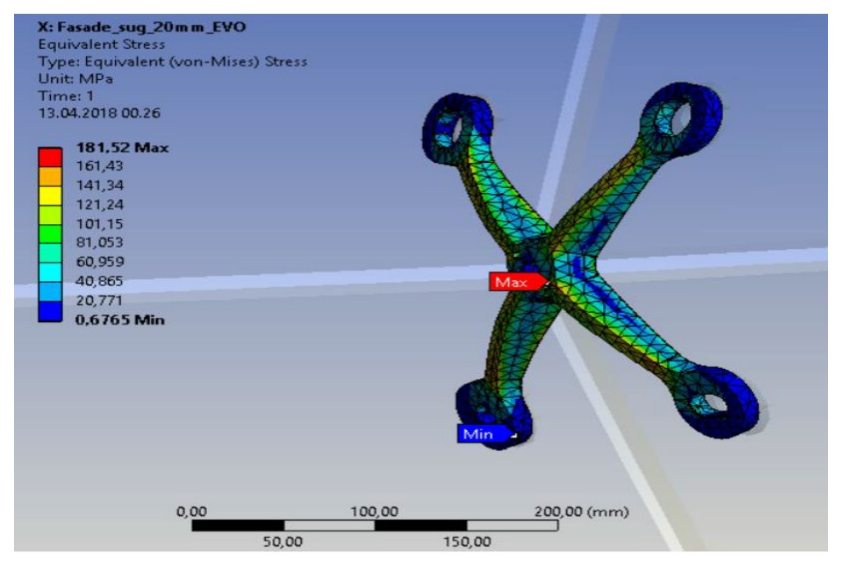

a

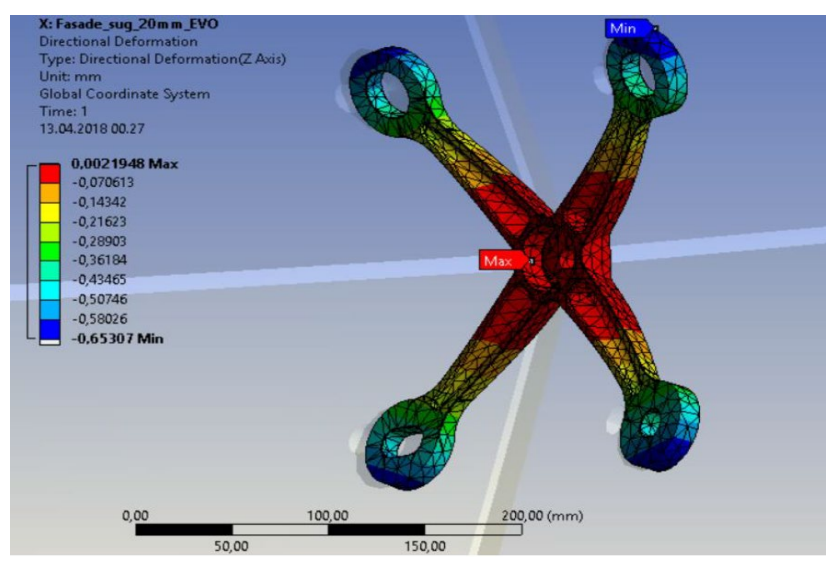

b

Figure 5. Case 3: a) Von Mises equivalent stress distribution; b) Spider deformation. 


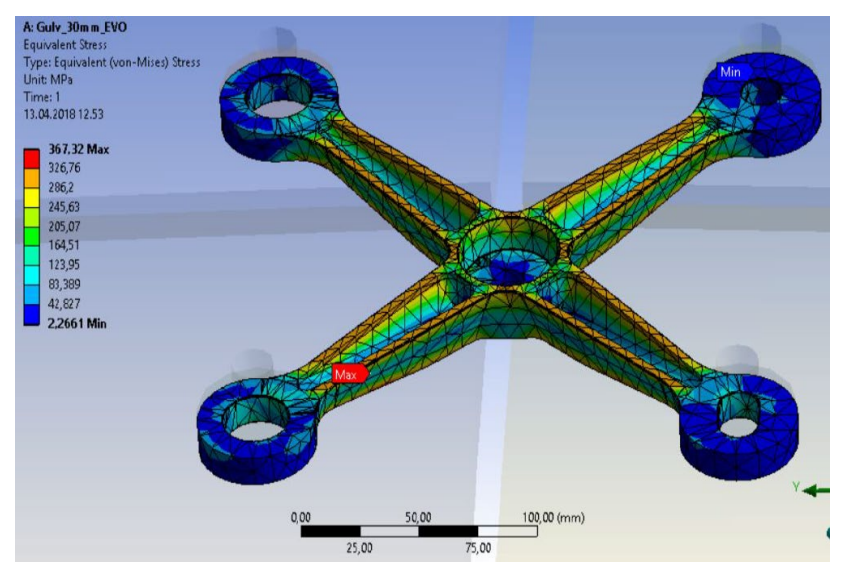

a

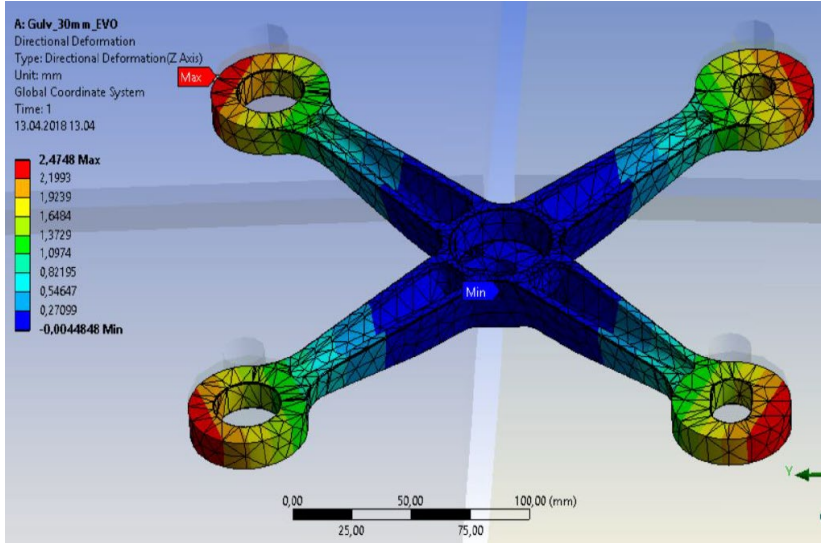

b

Figure 6. Case 6: a) Von Mises equivalent stress distribution; b) Spider deformation.

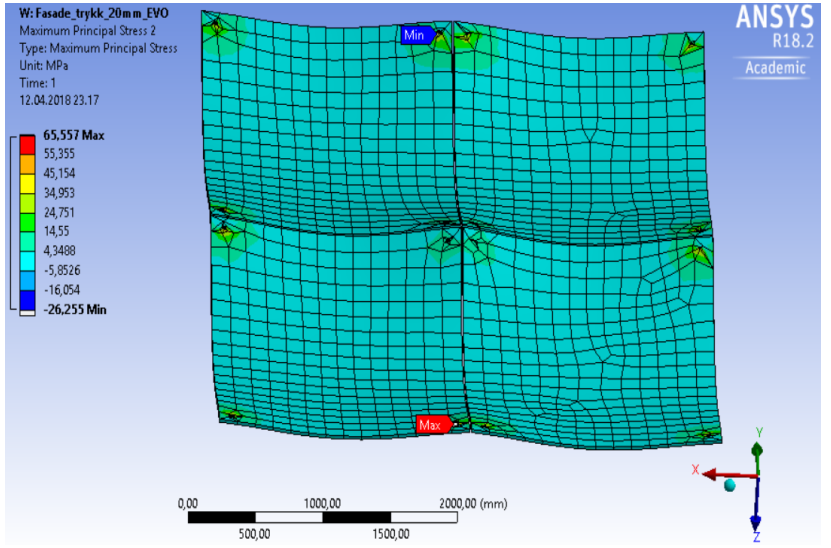

a

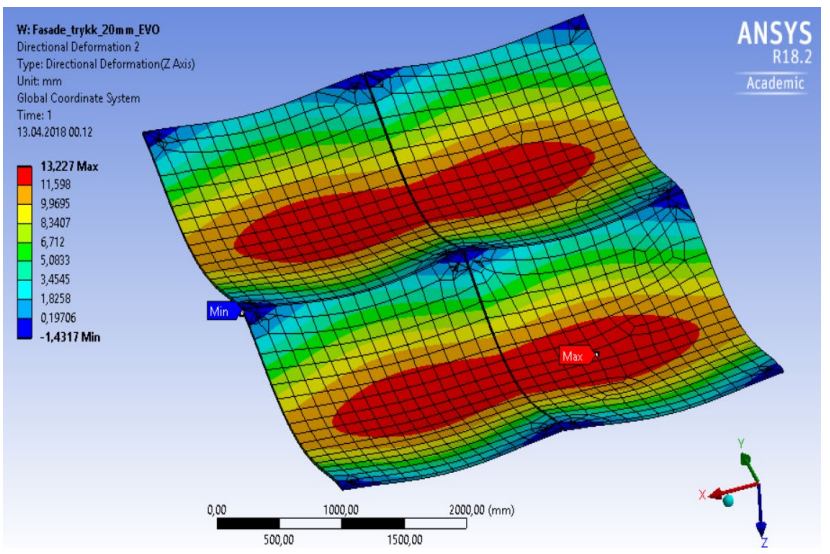

b

Figure 7. Case 1: a) Principal stress distribution; b) Glass deformation.

An overview of the results for all the case studies of the parametric study is presented in Table 3 .

Table 3. Overview of the results.

\begin{tabular}{|c|c|c|c|c|c|c|c|}
\hline Number & Placement & Spider & $\begin{array}{c}\text { Glass } \\
\text { thickness, } \\
{[\mathbf{m m}]}\end{array}$ & $\begin{array}{c}\boldsymbol{\sigma}_{\text {max,spider, }} \\
{[\mathbf{M P a}]}\end{array}$ & $\begin{array}{c}\boldsymbol{\delta}_{\text {max,spider, }} \\
{[\mathbf{m m}]}\end{array}$ & $\begin{array}{c}\boldsymbol{\sigma}_{\text {max,glass, }} \\
{[\mathbf{M P a}]}\end{array}$ & $\begin{array}{c}\boldsymbol{\delta}_{\text {max,glass, }} \\
{[\mathbf{m m}]}\end{array}$ \\
\hline 1 & Façade & Reference & 20 & 315.40 & 1.29 & 65.56 & 13.23 \\
\hline 2 & Façade & Reference & 30 & 288.00 & 0.80 & 19.56 & 4.90 \\
\hline 3 & $\begin{array}{c}\text { Façade } \\
\text { (suction) }\end{array}$ & Reference & 20 & 181.50 & -0.65 & 33.5 & -7.24 \\
\hline 4 & Façade & Modified v1 & 20 & 312.20 & 1.20 & 63.95 & 13.15 \\
\hline 5 & Façade & Modified v1 & 30 & 241.10 & 0.73 & 19.48 & 4.88 \\
\hline 6 & Floor & Reference & 30 & 367.30 & 2.47 & 128.37 & 23.57 \\
\hline 7 & Floor & Modified v1 & 30 & 322.20 & 1.29 & 41.70 & 8.85 \\
\hline 8 & Floor & Modified v2 & 30 & 299.50 & 0.98 & 40.66 & 8.75 \\
\hline 9 & Floor & Modified v3 & 30 & 332.60 & 0.85 & 40.36 & 8.70 \\
\hline 10 & Floor & Modified v4 & 30 & 276.80 & 0.98 & 40.62 & 8.74 \\
\hline 11 & Floor & Modified v4 & 35 & 274.00 & 0.88 & 27.00 & 6.11 \\
\hline 12 & Floor & Modified v4 & 40 & 280.80 & 0.83 & 18.60 & 4.45 \\
\hline
\end{tabular}




\section{Discussion}

The assumptions that were made during the numerical analysis of the glazing systems, such as to exclude bolts and seals as elements of the model or to model the glass as being monolithic, have a significant effect on the results. Regarding the stress measurements of the examined glazing systems, case 6 glazing system is found to have the highest generated stress, resulting in the collapse of the system. The developed equivalent von Mises stress of the spider in case 6 has a peak value of $367.3 \mathrm{MPa}$. This is expected since the reference spider is intended for façade and not for floor placement, where the load and support conditions are different. When a modified version of the spider replaces the reference one, such in cases 7-14, the generated stress in the spider decreases significantly.

Moreover, when comparing the generated deflections of the glazing systems, the minimum deflection of a spider is found in case 5 with a value equal to $0.73 \mathrm{~mm}$ whereas the maximum one in case 6 with a value equal to $2.47 \mathrm{~mm}$. As aforementioned, the glazing system of case 6 is the system with the maximum developed von Mises stress, so the calculation of the maximum deflection is in line with this observation. Regarding case 5 glazing system the use of maximum glass panel thickness directly affects the deflection of the system, thus resulting in reducing the deflection to the minimum value.

The presence of arm cavities proved to be beneficial for the spider and the corresponding glazing system. This point is justified after the comparison of the analysis results between modified versions 3 and 4 of the reference spider. In the first case of the modified version 3, the absence of cavities results in using more and not so effectively placed material whereas in the latter case, the spider is considerably lighter and performs similar or even better in terms of strength and deformation, comparing to the first case.

Overall, case 11 system is proved the more efficient, both between façade and floor placement systems, since it provides the best combination of adequate strength and limited deflection without significantly increasing the weight and the glass thickness in comparison to the reference system.

\section{Conclusions}

After the consideration of the results of the performed parametric study, the following conclusions can be derived:

- The structural behaviour of spiders is highly benefited from its sophisticated and complex geometric characteristics such as the presence of cavities and having a high arm to core ratio, as expected.

- Even a small increase in the thickness of the spider can significantly increase the resistance of the spider and the corresponding glazing system.

- Glass stiffness value is important since it is directly related to the control of the structural performance of the glazing system and the degree of interaction between glass and spider. In the presented analysis, the stiffness of the glass is calculated by the finite element software from the glass related data provided during the construction of the model.

- Structural spiders that are intended for façade placement can be used in floors with adequate results, if they are accompanied by thick glass panels.

- The deformations of the spiders are relatively small even when the load approaches the maximum strength capacity of the spider.

- Minimizing the number of simplifications together with the integration of thermal effects in the analysis can act as a guide for future research work in the field. A comparative numerical investigation of similar clamped glazing systems is also important in order to highlight the differences in response between bolted and clamped systems. 


\section{Conflict of Interest}

The authors declare no potential conflicts of interest that may be perceived as inappropriately influencing the representation or interpretation of reported research results.

\section{References}

[1] Y. Wang et al., Bearing capacity of non-linear metallic spiders used in point supported glass facades, International Journal of Steel Structures. 12(2) (2012) 191-204.

[2] M.M. El-Shami, Y.E. Ibrahim, M. Shuaib, Structural behaviour of architectural glass plates, Alexandria Engineering Journal. 49 (2010) 339-348.

[3] M. Rénes et al., Laboratory experiments of point fixed glasses, Journal of Silicate Based and Composite Materials. 67(2) (2015) 62-67.

[4] Z. Wang et al., Bearing capacity of tempered glass panel in point supported glass facades against in-plane load, Advances of Civil and Mechanical Engineering. 16(4) (2016) 935-948.

[5] S. Sivanerupan et al., Analytical study of point fixed glass facade systems under monotonic in-plane loading, Advances in Structural Engineering. 19(4) (2016) 611-626.

[6] C. Bedon et al., Performance of structural glass facades under extreme loads - Design methods, existing research, current issues and trends, Construction and Building Materials. 163 (2018) 921-937.

[7] B. Van Lancker et al., Durability of adhesive glass-metal connections for structural applications, Engineering Structures. 126 (2016) 237-251.

[8] M. Bues et al., Load bearing and failure behaviour of adhesively bonded glass-metal joints in façade structures, The Journal of Adhesion. (2019) 1-22. doi: $10.1080 / 00218464.2019 .1570158$

[9] M.A. Vyzantiadou, A.V. Avdelas, Point fixed glazing systems: technological and morphological aspects, Journal of Constructional Steel Research. 60 (2004) 1227-1240.

[10] A. Aksamija, Design methods for sustainable, high performance building facades, Advances in Building Energy Research. 10(2) (2016) 240-262.

[11] T. Hana et al., Determination of PVB interlayer's shear modulus and its effect on normal stress distribution in laminated glass panels, IMST2017- IOP Conference Series: Materials Science and Engineering. 251 (2017). doi:10.1088/1757-899X/251/1/012076

[12] Y. Wang et al., Experimental and numerical studies on the static and the dynamic behaviors of embedded cable support (ECS) glass facade system, Engineering Structures. 178 (2019) 521-533.

[13] M. Patterson, Structural glass facades and enclosures. John Wiley and Sons, New Jersey, 2011.

[14] M. Moastuen, Parametric numerical study of a spider system, MSc. Dissertation, Facult. of Scien. and Tech., Norweg. Univ. Of Life Sciences, Ås, Norway, 2018.

[15] Sadev, Attache S3001EVO-Essais Mécaniques. Test Report [Online]. Available: http://www.sadev.com

[16] ANSYS Inc., Ansys manual v18.2, Canonsburg (PE), USA, 2018.

[17] Luxion USA., KeyShot: 3D Rendering software, Tustin (CA), USA, 2018.

[18] EN 1990. Eurocode: Basis of structural design, CEN, 2002. 
[19] EN 1991-1-1. Eurocode 1: Actions on structures. Part 1-1: Densities, self weight and imposed loads, CEN, 2002.

[20] EN 1991-1-4. Eurocode 1: Actions on structures. Part 1-4: Wind loads, CEN, 2005.

[21] prEN 13474-3: Glass in building - Determination of the strength of glass panes. Part 3: General method of calculation and determination of strength of glass by testing. CEN/TC129, 2009. 